\title{
ARTIKELEN
}

\section{De stad als lab voor sociale verandering}

\author{
Philip Marcel Karré, Iris Vanhommerig \& Ellen van Bueren
}

De stad is in: de oplossingen voor allerlei hedendaagse wereldproblemen worden steeds meer op lokaal niveau gezocht. Het lokaal bestuur krijgt door de decentralisaties meer verantwoordelijkheden en er wordt veel verwacht van de pragmatische vaardigheden van burgemeesters. Ook wordt grote hoop gevestigd op het zelforganiserend vermogen van de stad, die als laboratorium wordt gezien voor sociale verandering en verbetering. In dit themanummer onderwerpen wij een aantal van de hoge verwachtingen ten aanzien van steden en het lokaal niveau aan een kritische beschouwing. Wat kunnen steden daadwerkelijk waarmaken en wanneer verwordt de 'hoop' tot een 'hype'? In dit inleidend artikel gaan we met name in op het idee dat in wijken en buurten door middel van zogenoemde living labs maatschappelijke vraagstukken op een laagdrempelige, innovatieve en pragmatische manier kunnen en moeten worden aangepakt.

\section{Inleiding}

Het is nog niet eens zo lang geleden dat steden vooral een negatief imago hadden. Zij werden gezien als vies, vol en gevaarlijk en als broeinesten voor maatschappelijke problemen. Teruglopende leefbaarheid, criminaliteit en allerlei vormen van economische en sociale achterstanden leken vooral steden te teisteren (Duyvendak, Hendriks, \& Van Niekerk, 2009). Wie kon, vertrok, bijvoorbeeld naar de voorsteden of naar een slaapstad, groeikern of New Town (Berg \& Geluk, 2009). Wie achter bleef, had vaak de middelen niet om de stad te ontvluchten en leefde in achterstandswijken met allerlei sociale spanningen: er was sprake van segregatie tussen wijken en buurten met 'kansarme' en met 'kansrijke' bewoners (Veldboer, Duyvendak, \& Bouw, 2007). Bestuurlijke en planologische ingrepen, met name vanuit een modernistisch perspectief gericht op maakbaarheid, verlichtten de problemen niet, maar, volgens bijvoorbeeld Jacobs (1961), verergerden of veroorzaakten ze zelfs. Veel steden waren in verval (Skifter Andersen, 2003) en menigeen beklaagde zelfs de dood van de (met name postindustriële) stad (zie over dit debat bijvoorbeeld Newton, 1986).

Die tijden zijn voorbij. De stad is niet dood, integendeel (Hall, 2003). Steden zijn terug van weggeweest, worden herontdekt en zijn bezig met een heuse triomftocht (Glaeser, 2011): meer en meer mensen willen er wonen (of moeten dat doen, om te overleven, zie bijvoorbeeld Sanders, 2010) en steden worden gezien als de powerhouses van onze nieuwe, met name creatieve en dienstenindustrie (Florida, 2002; 2005; 2008). Ook zien we een verschuiving van hoe naar de stad wordt gekeken als het gaat om de aanpak van maatschappelijke problemen: was 
zij voorheen vooral de plaats of context waar die problemen zich voordeden of konden ontstaan, zo is de stad inmiddels in veel van het maatschappelijke, politieke en wetenschappelijke debat veranderd tot juist dé bestuurslaag om deze maatschappelijke problemen op te pakken en op te lossen. $\mathrm{Nu}$ is het de natiestaat die af heeft gedaan. Stadsbestuurders, met name burgemeesters, worden in invloedrijke publicaties gepresenteerd als nieuwe helden (Bradley \& Katz, 2013; Barber, 2013). Zij zijn daadkrachtige Macher en door pragmatisme gedreven probleemoplossers. Niet de ideologie, maar het geboekte resultaat voor de burger telt.

De oplossingen voor allerlei hedendaagse wereldproblemen (terrorisme, klimaatverandering, migratie, et cetera) lijken steeds meer op lokaal niveau te worden gezocht. Ook klassieke overheidsverantwoordelijkheden worden nu vaker op dat niveau belegd. Zo krijgen in Nederland decentrale overheden nieuwe taken en worden stelsels van publieke voorzieningen herzien, ${ }^{1}$ met een fundamentele aanpassing van de klassieke verzorgingsstaat als gevolg, zo schrijft bijvoorbeeld SCPdirecteur Putters: 'De Nederlandse verzorgingsstaat transformeert richting een verzameling verzorgingssteden. Zorg, arbeid, onderwijs, huisvesting en welzijn liggen steeds nadrukkelijker op het bordje van gemeenten en van burgers zelf.' (Putters, 2013).

In tijden van verdergaande decentralisatie en de (vermaarde) opkomst van de participatiesamenleving zijn het niet alleen de bestuurders van steden die een belangrijke rol toegedicht krijgen in de aanpak van maatschappelijke vraagstukken. Juist op lokaal niveau, in de wijken en buurten van steden en andere gemeenten, zijn burgers steeds nadrukkelijker actief: 'Veel steden barsten bijna uit hun voegen van allerlei bruisende, sociale initiatieven' (De Boer \& Van der Lans, 2013). Innovatie en creativiteit staan daarbij voorop: de stad wordt gezien als een heus sociaal laboratorium, waarin geëxperimenteerd wordt met leuke, vernieuwende manieren om allerlei problemen op te lossen en maatschappelijke meerwaarde te creëren. In living labs werken overheden, bedrijven en kennisinstellingen samen. Daarnaast krijgen burgers als eindgebruikers van veel publieke voorzieningen een belangrijke rol: zij zijn niet alleen coproducenten, maar vaak leidend in dit proces. Er wordt veel verwacht van het zelforganiserend vermogen van de stad (zie bijvoorbeeld Uitermark, 2012; De Boer \& Van der Lans, 2014; Miazzo \& Kee, 2014; Schleijpen \& Leatemia, 2014).

In dit themanummer onderwerpen wij een aantal van de hoge verwachtingen ten aanzien van steden en het lokaal niveau aan een kritische beschouwing. Wat kunnen steden er daadwerkelijk van waarmaken en wanneer verwordt de 'hoop' tot een 'hype'? Wij sluiten daarbij aan bij de drie themanummers die Bestuurskunde de afgelopen jaren reeds aan het onderwerp stad heeft gewijd:

- In het winternummer 2010 hebben wij aandacht besteed aan urban governance en wat meervoudige manieren van sturing betekenen voor steden en hun bestuurders. 
- In het voorjaarsnummer van 2012 hebben wij een aantal grootstedelijke vraagstukken belicht, alsook de vraag gesteld welke nieuwe vormen van collectief handelen daar bij passen.

- En in het herfstnummer van 2013 hebben wij besproken, wat het betekent dat gemeenten zich vaak als eerste overheid zien en zich naar buiten toe ook zo presenteren.

Ook sluiten we aan bij de themanummers die we aan zelfsturing en -regulering hebben gewijd en doen we een voorschot op het aankomend themanummer over burgerparticipatie (zomer 2015).

In dit inleidend artikel gaan we met name in op het concept living lab en de verwachtingen die er aan gekoppeld worden in de aanpak van maatschappelijke vraagstukken. De stad is een belangrijke experimenteerruimte geworden, een proeftuin of broedplaats voor nieuwe praktijken, die op een kleinschalige en laagdrempelige manier met betrokkenheid van de eindgebruiker worden ontwikkeld en getest. In dit artikel staan we kritisch stil bij deze ontwikkeling, alsook de verwachtingen en overtuigingen die erachter schuilgaan. Onze centrale vraag in dit artikel luidt: wat betekent de focus op de stad als lab precies, wat kunnen we ervan verwachten en wat moeten we doen om die verwachtingen waar te maken?

\section{Theoretisch achtergrond}

Het concept 'living lab', vaak ook aangeduid als 'urban lab' of 'field lab', heeft de afgelopen paar jaar vleugels gekregen in discussies over stedelijke vernieuwing en het onderzoek ernaar. Wat het precies betekent en hoe het zich als verander- en onderzoeksinstrument onderscheidt van andere tools, is echter vaak niet helemaal duidelijk. In toepassingen gericht op veranderingen in grootstedelijk beleid met politiek en maatschappelijk draagvlak is dat misschien ook niet echt erg; het gaat er dan immers om concepten te gebruiken, die energie losmaken en door iedereen op verschillende manieren kunnen worden ingevuld. Maar deze vaagheid geeft ook de zwakte aan van het concept, in elk geval van hoe het in de Nederlandse beleidscontext wordt ingevuld. Er wordt, net als van steden en hun bewoners, veel verwacht van living labs en men kan zich afvragen of zij die verwachtingen daadwerkelijk kunnen waarmaken. Ook interessant is om te bekijken hoe living labs zich verhouden tot andere governance-achtige arrangementen waarbij bewoners een centrale rol spelen in veranderpraktijken op lokaal niveau.

Het idee achter het living lab komt oorspronkelijk uit de techniek en wordt vaak toegeschreven aan de aan het MIT Media Lab verbonden professor William J. Mitchell (Dutilleul, Birrer, \& Mensink, 2010, p. 63). Door de technische vooruitgang en de mogelijkheden die hedendaagse ICT biedt (denk bijvoorbeeld aan de Internet of Things, maar ook Web 2.0 en sociale media) zag Mitchell een kans om bij onderzoek naar innovatie in met name domotica (huisautomatisering) de gebruiker er gelijk bij te betrekken, zoals bijvoorbeeld ook gebruikelijk is in Design Thinking, een andere hippe term, die is komen overwaaien uit de wereld van de 
(technische) productontwikkeling (zie bijvoorbeeld Brown, 2009; Dorst, 2011). Al snel werd de methodiek van het living lab opgepakt in andere contexten en ook gebruikt voor de aanpak van allerlei maatschappelijke vraagstukken (logistiek, wonen, zorg, welzijn, onderwijs, duurzaamheid, et cetera). Hierdoor zijn er internationaal honderden van dit soort labs actief, bijvoorbeeld verbonden in de European Network of Living Labs (ENoLL). In Nederland zijn living labs in steeds meer steden en gemeenten te vinden.

Door de brede toepassing, heeft de term living lab inmiddels meer dan één invulling gekregen. In hun overzichtsartikel over living labs als instrumenten in sociale innovatie beschrijven Dutilleul, Birrer en Mensink (2010, p. 64) er vijf:

'[Living lab] may refer to (1) an innovation system consisting of organised and structured multi-disciplinary networks fostering interaction and collaboration, (2) in vivo monitoring of a "living" social setting generally involving experimentation of a technology, (3) an approach for involving users in the product development process, or (4) organisations facilitating the network, maintaining and developing its technological infrastructure and offering relevant services; finally, the term may also refer to (5) the eponymous European movement.'

Er bestaat dus geen alomvattende, breed gedragen definitie van wat een living lab is, maar op basis van hun onderzoek naar overkoepelende kenmerken van een aantal ervan beschrijven Bergvall-Kareborn en Stahlbrost (2009) een living lab als volgt:

'A Living Lab is a user-centric innovation milieu built on every-day practice and research, with an approach that facilitates user influence in open and distributed innovation processes engaging all relevant partners in real-life contexts, aiming to create sustainable values.'

Door deze brede definitie en verschillende invullingen vertoont het begrip overeenkomsten met verwante concepten als open innovation (Chesbrough, 2009), crowdsourcing (Howe, 2009) en de interactieve mogelijkheden van web $2.0^{2}$ (O’Reilly, 2005; Vanhommerig \& Karré, 2014). Net zoals deze worden living labs met name gebruikt in de aanpak van maatschappelijke vraagstukken, die, omdat zij complex, betwist en kokeroverstijgend zijn, vaak als hardnekkig (of wicked) worden aangeduid en daarom vragen om een multidisciplinaire aanpak. Steeds gaat het erom, dat de aanpak voor het vraagstuk in kwestie in samenwerking met de eindgebruiker moet worden ontwikkeld in een proces, waarin vijf kernwaarden centraal staan: openheid, daadwerkelijke invloed van alle betrokkenen, realisme, focus op de creatie van meerwaarde, en duurzaamheid (Bergvall-Kareborn \& Stahlbrost, 2009). In de context waarin living labs zijn ontwikkeld, techniek en bedrijfsleven, zijn de eindgebruikers met name consumenten van nieuwe techni- 
sche toepassingen (denk aan allerlei vernuftige snufjes in Smart Houses, zoals zelfregelende thermostaten of koelkasten, die zelf de boodschappen doen). In het publieke domein zijn de eindgebruikers burgers in de rol van consumenten van overheidsdiensten.

\section{Discussie}

Hoe past dit nieuwe concept in de bestaande bestuurskundige kennis? In hoeverre is het daadwerkelijk 'nieuw'? Het betrekken van de eindgebruiker in het ontwikkelproces is natuurlijk geen nieuw concept. Elmore (1979) schreef al over 'backward mapping', waarbij het beleidsontwerp begint bij de kenmerken en het gedrag van de eindgebruiker, in tegenstelling tot de top-down ontwerpstrategie van 'forward mapping'. Ook interactieve beleidsvoering (Edelenbos, 2000) en coproductie met de burger in talloze verschillende verschijningsvormen en gradaties van participatie (Pröpper, 2009) zijn allesbehalve nieuwe verschijnselen.

Hoewel er over de resultaten van living labs nog niet veel bekend is, weten we uit onderzoek naar vergelijkbare vormen van coproductie dat de voordelen die ook aan living labs worden toegeschreven, niet altijd worden waargemaakt. Directe participatie van burgers wordt vaak aangeprezen als 'democratischer' dan besluitvorming door volksvertegenwoordigers (voor een kritische reflectie zie Michels, 2011), maar we weten ook dat vooral bepaalde groepen burgers de weg naar deze inspraak- en meebeslismogelijkheden weten te vinden (zie bijvoorbeeld Uitermark, 2014). Intensieve vormen van participatie kosten tijd en energie, en lang niet iedereen zal de gepercipieerde opbrengst die investering waard vinden. Die kosten-batenafweging zal vooral positief uitvallen als de opbrengst hoog, of de investering laag is. Oftewel: voor diegenen die veel te winnen of te verliezen ("not in my backyard!') hebben bij een besluit, ofwel hoogopgeleid zijn, waardoor deelname aan een living lab hen niet al te veel extra tijd en moeite kost. De veelgeprezen eindgebruiker is dus lang niet altijd makkelijk te inventariseren en te betrekken, zeker als die tot de groep 'kansarme' stadsbewoners behoort.

Een tweede belemmering waarmee naar ons idee in veel van de lofzangen op steden en living labs nauwelijks rekening wordt gehouden, betreft het vraagstuk van de verduurzaming. Wat living labs charmant en aantrekkelijk maakt, is hun kleinschaligheid en laagdrempeligheid, maar ook het idee dat door de geografische afbakening en betrokkenheid van de direct belanghebbenden maatwerk mogelijk wordt. Voor het vraagstuk in kwestie is dat inderdaad een niet te onderschatten voordeel, maar het maakt het vervolgens ook ingewikkeld om projecten en op één plek beproefde oplossingen op te schalen en/of ook op andere plekken tot uitvoering te brengen, die per definitie verschillende kenmerken zullen hebben. Daar komt ook nog bij dat de verantwoording over de daadwerkelijk geboekte resultaten vaak niet aanwezig of gebrekkig is. Hierdoor weten we vaak niet wat van alle hoge verwachtingen ook daadwerkelijk in de praktijk is gebracht, en wordt ons de mogelijkheid ontnomen om te leren van wat goed ging en fout liep, waardoor de bredere toepassing van de in het living lab geboekte innovaties ook weer in het 
geding komt. Dat is met name belangrijk, omdat het succes van living labs staat en valt met de kwaliteit van de samenwerking en hun multidisciplinaire aanpak: beide zijn vaak alles behalve dan een sinecure, met name omdat waarden en belangen van de verschillende betrokken partijen natuurlijk altijd óók een rol spelen.

Dat brengt ons tot de laatste, maar zeker meest belangrijke kanttekening die naar ons idee te trekken is bij het concept van het living lab en de hoge politieke en maatschappelijke verwachtingen die erachter schuilgaan. De keuze om de aanpak voor een bepaald vraagstuk in samenwerking te ontwikkelen tussen verschillende partijen en met bijzondere aandacht voor de eindgebruiker in de vorm van een living lab, is allesbehalve pragmatisch en apolitiek. In veel beschouwingen over de stad als lab (zie bijvoorbeeld De Boer \& Van der Lans, 2013) wordt vaak afgegeven op meer traditionele manieren van politieke wilsvorming en de rol daarin van wat als 'de oude garde' wordt neergezet. Misschien dat dit het succes verklaart van een manier om sociale innovatie te bewerkstelligen die niet ideologisch overkomt, maar afkomstig is uit het bedrijfsleven en daar wordt ingezet om tot allerlei technische productinnovaties te komen. In het publieke domein hebben wij echter niet te maken met producten die wij zo goed mogelijk moeten afstemmen op de wensen en behoeften van de consument (de vermaarde eindgebruiker). De vraagstukken waarmee steden en hun bewoners te maken hebben, zijn toch net wat ingewikkelder en de groep burgers als eindgebruikers is toch wat diverser.

Spreken deze kanttekeningen allemaal tegen het gebruik van living labs? Nee, maar ze laten wel zien, dat het vaak niet gemakkelijk is om methoden en technieken uit andere contexten zomaar in het publieke domein van de grote stad te droppen en toe te passen. Ook is het belangrijk om te waarschuwen voor al te hoge verwachtingen en het gebrek aan een adequate verantwoording en mogelijkheden om te leren. In de stad staat veel op het spel en daarom is het belangrijk om niet naïef te zijn in de aanpak van grootstedelijke vraagstukken. Het komt misschien lekker stoer en daadkrachtig over om pragmatisch en met een duidelijke missie en visie te werk te gaan. De ervaring leert echter dat deze aanpak in het publieke domein vaak niet tot de gewenste resultaten leidt (De Bruijn \& Ten Heuvelhof, 2007).

\section{Verdere opbouw themanummer}

Naast deze inleiding en kritische beschouwing van het fenomeen living lab bevat dit themanummer een aantal artikelen die verschillende van de verwachtingen belichten waar steden en het lokaal niveau in het algemeen mee te maken hebben. Omdat wat er op dit moment daar gebeurt vrij divers is en tot gevarieerde praktijken leidt, hanteren wij eveneens een breed en met name agenderend en verkennend perspectief. Wij hopen zodoende tot een rijk geschakeerd beeld te komen van wat op dit moment gebeurt in de praktijken van en rond steden en hoe je er als bestuurskundige onderzoeker en practitioner naar kunt kijken. 
Robert Duiveman sluit in zijn bijdrage aan bij de verwachtingen die wij in dit inleidend artikel schetsen over hoe de stad als lab kan bijdragen aan maatschappelijke verbetering en vooruitgang. Hij kijkt daarvoor naar nieuwe kennisarrangementen om tot een breed gedragen aanpak te komen voor maatschappelijke problemen in steden. Er zijn nieuwe kennisarrangementen nodig om te bepalen wat er in een gegeven situatie aan de hand is en hoe er het beste mee kan worden omgegaan. Dit doet zich duidelijk voor in discussies rondom de aanpak van weerbarstige stedelijke problemen. Tegen deze achtergrond zijn in het onderzoeksprogramma Kennis voor Krachtige Steden van Platform31 consortia van wetenschappers en stedelijke partijen gevormd. Duiveman gebruikt dit programma als casestudy voor zijn beschouwing en om lessen te trekken voor het verbeteren van adequate kennispraktijken rondom stedelijke vraagstukken.

Martijn van der Steen en Ilsa de Jong haken in hun bijdrage aan bij de verwachtingen ten aanzien van burgemeesters als pragmatische en resultaatgedreven probleemoplossers par excellence. Zij laten zien hoe burgemeesters zich vandaag de dag soepel moeten bewegen in een aantal netwerken en hoe deze nieuwe rol zich verhoudt tot hun meer klassieke verantwoordelijkheden.

Henk de Jong, voormalig gemeentesecretaris van Amsterdam, neemt de discussie rondom de positie van burgemeesters naar aanleiding van het boek van Benjamin Barber als uitgangspunt voor zijn betoog, dat hij eind 2014 heeft uitgesproken als Van Slingelandt-lezing. Als bestuurskundige die de afgelopen jaren in New York heeft gewoond en gewerkt, kijkt De Jong kritisch naar hoe in het gesprek inzichten uit de VS onkritisch worden overgenomen. Ook laat hij zien dat je ook daar de uitspraken over de nieuwe rol van steden met een korreltje zout moet nemen. Zijn Van Slingelandt-lezing wordt aangevuld door het co-referaat, dat Klaartje Peters heeft verzorgd.

Martin de Jong, Simon Joss, Daan Schraven, Changjie Zhan en Margot Weijnen staan in hun bijdrage stil bij de verwachtingen achter de eco-city en het begrip duurzaamheid in een stedelijke context. Duurzaamheid is een van de grootste uitdaging voor steden: politiek en maatschappij verwachten van hen om met name hier resultaat te boeken. Denk hierbij bijvoorbeeld aan de discussies over onderzoek dat aantoont dat Rotterdammers vanwege de vuile lucht in hun stad drie jaar eerder doodgaan dan andere Nederlanders. Ook in dit debat buitelen verschillende begrippen en concepten over elkaar heen, zoals 'sustainable cities', 'green cities', 'digital cities', 'intelligent cities', 'smart cities', intelligent cities', 'information cities', 'knowledge cities', 'resilient cities'; 'eco-cities', 'low carbon cities' en 'liveable cities'. Net als bij het begrip living lab worden deze concepten vaak voor elkaar ingewisseld en is niet altijd even duidelijk wat ermee bedoeld wordt; in elk geval, zo blijkt uit de toepassing ervan in beleidsteksten en de maatschappelijke en politieke discussie, 'bekken ze wel lekker'. In hun bijdrage proberen De Jong, Joss, Schraven, Zhan en Weijnen orde te brengen in dit debat. Op basis van een uitgebreide literatuurstudie hebben zij de betekenis ontfutseld van alle genoemde begrippen en wat zij voor steden, hun bestuurders en bewoners betekenen. Op 
deze manier brengen zij scherpte en nuance in een debat dat last heeft van een lawine van concurrerende begrippen en invullingen.

Naast wetenschappelijke artikelen bevat dit themanummer ook twee praktijkreflecties. Gerard Nijboer schetst hoe in Rotterdam wordt gewerkt aan, in en met living labs. En Willem van Winden beschrijft aan de hand van een aantal cases in binnen- en buitenland de uitdagingen rondom deze samenwerkingsverbanden.

Wij sluiten het themadeel af met een bijdrage waarin wij de conclusies samenvatten van de afzonderlijke bijdragen. Op basis daarvan schetsen wij een onderzoeksen praktijkagenda, die recht doet aan de gevarieerde praktijken die vandaag de dag in steden te vinden zijn.

\section{Literatuur}

Barber, B. (2013). If mayors ruled the world: Dysfunctional nations, rising cities. Yale: Yale University Press.

Berg, J.J., \& Geluk, M. (red.). (2009). Vernieuwing van de nieuwe stad: Groeikernen van slaapstad naar droomstad. Almere: International New Town Institute.

Bergvall-Kareborn, B., \& Stahlbrost, A. (2009). Living Lab - An Open and Citizen-Centric Approach for Innovation. International Journal of Innovation and Regional Development, 1(4), 356-370.

Boer, N. de, \& Lans, J. van der. (2013). De verzorgingsstaat voorbij. De Groene Amsterdammer, 2 oktober, https://www.groene.nl/artikel/de-verzorgingsstaat-voorbij.

Boer, N. de, \& Lans, J. van der. (2014). DEcentraal. De stad als sociaal laboratorium. Amsterdam: Atlas Contact.

Bradley, J., \& Katz, B. (2013). The metropolitan revolution: How cities and metros are fixing our broken politics and fragile economy. Washington, DC: Brookings Institution Press.

Brown, T. (2009). Change by design. New York, NY: Harper Collins.

Chesbrough, H. (2009). Open innovation: The new imperative for creating and profiting from technology. Harvard, MA: Harvard Business School Press.

Dutilleul, B., Birrer, F.A.J., \& Mensink, W. (2010). Unpacking European Living Labs: Analysing Innovation's Social Dimensions. Central European Journal of Public Policy, 4(1): 60-85.

Dorst, K. (2011). The core of 'design thinking' and its application. Design Studies, 32(6), 521-532.

De Bruijn, H., \& Heuvelhof, E. ten. (2007). Management in netwerken: Over veranderen in een multi-actorcontext. Den Haag: Uitgeverij Lemma.

Duyvendak, J.W., Hendriks, F., \& Niekerk, M. van. (Eds.). (2009). City in sight: Dutch dealings with urban change. Amsterdam: Amsterdam University Press.

Elmore, R.F. (1979). Backward mapping: Implementation research and policy decisions. Political Science Quarterly, 94(4), 601-616.

Edelenbos, J. (2000). Proces in vorm: Procesbegeleiding van interactieve beleidsvorming over lokale ruimtelijke projecten. Utrecht: Uitgeverij Lemma.

Elmore, R.F. (1979). Backward mapping: Implementation research and policy decisions. Political Science Quarterly, 94(4), 601-616.

Florida, R. (2002). The rise of the creative class: And how it's transforming work, leisure, community, and everyday life. New York, NY: Basic Books. 
Florida, R. (2005). The flight of the creative class: The new global competition for talent. New York, NY: Harper Business.

Florida, R. (2008). Who's your city? How the creative class is making where to live the most important decision of your life. New York, NY: Basic Books.

Glaeser, E. (2011). Triumph of the city: How our greatest invention makes us richer, smarter, greener, healthier, and happier. London: Penguin.

Hall, P. (2003). The end of the city? 'The report of my death was an exaggeration'. City, 7(2), 141-152.

Howe, J. (2009). Crowdsourcing: How the power of the crowd is driving the future of business. New York, NY: Random House.

Jacobs, J. (1961). The death and life of great American cities. New York, NY: Random House.

Miazzo, F., \& Kee, T. (Eds.). (2014). We own the city: Enabling community practice in architecture and urban planning in Amsterdam, Hong Kong, Moscow, New York and Taipei. Haarlem/Valiz: Trancity.

Michels, A. (2011). De democratische waarde van burgerparticipatie: Interactief bestuur en deliberatieve fora. Bestuurskunde, 20(2), 75-84.

Newton, K. (1986). The death of the industrial city and the urban fiscal crisis. Cities, 3(3), 213-218.

O'Reilly, T. (2005). What is web 2.0? Design patterns and business models for the next generation of software. http://www.oreilly.com/pub/a//web2/archive/what-is-web-20.html.

Pröpper, I. (2009). De aanpak van interactief beleid. Bussum: Coutinho.

Putters, K. (2013). Het smalle pad van verzorgingsstaat naar verzorgingsstad.http://www. socialevraagstukken.nl/site/2013/05/25/het-smalle-pad-van-verzorgingsstaat-naarverzorgingsstad/.

Sanders, D. (2010). De trek naar de stad. Amsterdam: Bezige Bij.

Schleijpen, R., \& Leatemia, L. (2014). Pioniers in de stad: Wijkondernemers delen kennis en praktijk. Haarlem: Trancity/Valiz.

Skifter Andersen, H. (2003). Urban sores: On the interaction between segregation, urban decay and deprived neighbourhoods. Aldershot: Ashgate.

Uitermark, J. (2012). De zelforganiserende stad. In Raad voor de Leefomgeving en Infrastructuur (red.), Essays toekomst van de stad. (pp. 5-9) Den Haag: Rli.

Uitermark, J. (2014). Verlangen naar Wikitopia. Rotterdam: Erasmus Universiteit Rotterdam.

Vanhommerig, I., \& Karré, P.M. (2014). Public accountability in the internet age: Changing roles for governments and citizens. International Review of Public Administration, 19(2), 206-217.

Veldboer, L., Duyvendak, J.W., \& Bouw, C. (red.). (2007). De mixfactor: integratie en segregatie in Nederland. Amsterdam: Boom. 